\title{
RECOBRIMENTO DE SEMENTES DE CENOURA OSMOCONDICIONADAS ${ }^{1}$
}

\author{
LETÍCIA DOS SANTOS HÖLBIG ${ }^{2}$, LEOPOLDO BAUDET ${ }^{3}$, \\ FRANCISCO AMARAL VILLELA ${ }^{4}$, VIOLETA CAVALHEIRO ${ }^{5}$
}

\begin{abstract}
RESUMO - A produção de hortaliças desempenha um papel de grande importância socioeconômica, pois emprega uma grande quantidade de mão-de-obra .O objetivo no trabalho foi avaliar o desempenho fisiológico de sementes de cenoura após osmocondicionamento, tratamento com fungicida e recobrimento com polímero. Foram utilizadas sementes de cenoura, cv. Brazlândia, fornecidas pela Hortec, Bagé/RS, submetidas ao condicionamento osmótico com solução aerada de polietilenoglicol (PEG 6000) a -0,8 MPa por um período de 10 horas. A seguir as sementes foram lavadas com água destilada e submetidas à secagem em estufa com circulação de ar até atingirem a umidade de 7\%. As sementes foram tratadas com o fungicida Captan 750 TS $^{\circledR}(750$ g i.a.) na dose de $0,2 \%$ e recobertas com o polímero Colorseed ${ }^{\circledR}$ na dose de $50 \mathrm{~mL} \cdot \mathrm{kg}^{-1}$. As sementes foram submetidas aos seguintes tratamentos: sem osmocondicionamentos (SO), com osmocondicionamento (CO), sem polímero (SP), com polímero (CP), sem fungicida (SF) e com fungicida (CF), constituindo as seguintes combinações: 1) SO SP SF, 2) SO CP SF, 3) SO SP CF, 4) SO CP CF, 5) CO SP SF, 6) CO CP SF, 7) CO SP CF e 8) CO SP CF. As sementes foram submetidas aos testes de germinação, frio, envelhecimento acelerado modificado, emergência em casa de vegetação, índices de velocidade de germinação e emergência, comprimento de plântula e fitomassa fresca e seca da planta. O delineamento experimental foi completamente casualizado em fatorial 2 (com e sem osmocondicionamento) x 4 (tratamentos de recobrimento), com quatro repetições e as médias comparadas pelo teste de Duncan no nível de 5\% de significância. Conclui-se que o osmocondicionamento de sementes de cenoura favorece as velocidades de germinação e de emergência das plântulas; o uso de polímero e fungicida em sementes de cenoura osmocondicionadas não afetam negativamente o vigor das plântulas; independentemente do recobrimento e/ou tratamento com fungicida sementes osmocondicionadas apresentam desempenho superior.
\end{abstract}

Termos para indexação: Daucus carota, priming, polímero, tratamento químico, qualidade fisiológica.

\section{COATING OF PRIMED CARROT SEEDS}

\begin{abstract}
Vegetable production plays a major socio-economic role because it is labor intensive. The objective of this study was to evaluate the physiological performance of carrot seed after priming (osmotic preconditioning), fungicide treatment and polymer film coating. Carrot seeds cv.
\end{abstract}

${ }^{1}$ Submetido em 05/05/2009. Aceito para publicação em 30/08/2010. Parte da dissertação do primeiro autor apresentada à UFPel.

${ }^{2}$ Eng. Agr, pós graduanda do Programa de Pós Graduação C\&T de Sementes -FAEM/UFPel, 1sholbig@yahoo.com.br

${ }^{3}$ Eng. Agr, Ph.D., Professor Titular, do Programa de Pós Graduação C\&T de Sementes - FAEM/UFPel, lmbaudet@ufpel.edu.br
${ }^{4}$ Eng. Agrícola, Dr., Professor Associado do Programa de Pós-Graduação em Ciência e Tecnologia de Sementes, FAEM/UFPel. Caixa Postal 354, CEP 96010-900 Pelotas, RS. E-mail: francisco.villela@ufpel.edu.br.

${ }^{5}$ Aluna do Curso de Engenharia Agronômica, bolsista PIBIC/CNPq FAEM/UFPel. 
Brazlândia were provided by Hortec, Bagé / RS and submitted to priming with an aerated solution of polyethylene glycol (PEG 6000) at - 0.8 MPA for 10 hours. Seeds were then rinsed with distilled water and oven dried until moisture content was $7 \%$. The seeds were treated with Captan $750 \mathrm{TS}^{\circledR}$ ( $750 \mathrm{~g}$ a.i.) fungicide at a dosage of $0.2 \%$ and coated with the polymer Colorseed ${ }^{\circledR}$ at a dosage of 50 ml. $\mathrm{kg}^{-1}$. Seed treatments were: no osmoconditioning (NCOND), with osmoconditioning (COND), no polymer (SP), with polymer (CP), no fungicide (SF) and with fungicide (CF), making up the following combinations: 1) NCOND SP SF, 2) NCOND CP SF, 3) NCOND SP CF, 4) NCOND CP CF, 5) COND SP SF, 6) COND CP SF, 7) COND SP CF e 8) COND SP CF. Seed quality was evaluated using the following tests: germination, cold, modified accelerated aging, greenhouse emergence, germination and emergence velocity index, seedling length, seedling dry and fresh matter weight. The statistical design was completely randomized in a 2 (primed and not-primed seeds) x 4 (treatments with fungicide and polymer) factorial, with four replications. Averages were compared by the Duncan test at the 5\% significance level. Osmoconditioning increases the speed of germination and seedling emergence; the application of polymer and fungicide on osmoconditioned carrot seed did not affect seedling vigor and regardless of the coating and/or fungicide treatment, the osmoconditioned seeds performed better.

Index terms: Daucus carota, priming, polymer, chemical treatment, physiological quality.

\section{INTRODUÇÃO}

A produção de hortaliças apresenta importante papel socioeconômico, pelo elevado emprego de mão-de-obra.

Para sustentar a área produtora, o Brasil dependia da importação de sementes provenientes de países europeus, Estados Unidos e Japão. Com o lançamento das cultivares Brasília e Kuronan, criou-se a opção de produção de sementes de cenoura no Brasil possibilitando, a partir de então, sensível diminuição na importação (Viggiano, 1990; Cardoso e Della Vecchia, 1995).

A baixa qualidade fisiológica das sementes de cenoura é atribuída à diferença no período de maturação entre as umbelas de diferentes ordens de uma mesma planta. Esta pode variar em até três semanas, mas dependendo das condições climáticas e da cultivar, pode atingir até 60 dias. Logo, um lote comercial pode apresentar diferentes estádios de maturação, e portanto, diversos tamanhos de sementes, o que refletirá diretamente na porcentagem e velocidade de germinação. Devido aos métodos de produção inadequados, tem sido observada uma baixa qualidade fisiológica das sementes, acarretando aumento da densidade de semeadura e consequentemente, onerando ainda mais insumos a cargo do produtor (Nascimento e Guedes, 1989).

O condicionamento osmótico de sementes pode beneficiar diretamente o desempenho de lotes de sementes, ao promover redução do período de germinação e emergência das plântulas, além de favorecer a tolerância a condições de estresse após a semeadura como, por exemplo, a baixa disponibilidade de água (Finch-Savage, 1995; Caseiro e Marcos Filho, 2005). Esse tratamento consiste na hidratação controlada das sementes, ativando os processos metabólicos necessários para a germinação sem, no entanto, permitir a protrusão da raiz primária. Apesar de sua influência sobre a velocidade, a sincronização e a percentagem de germinação, a utilização comercial do condicionamento fisiológico ainda é relativamente baixa (Nascimento, 1998).

Os fundamentos do condicionamento osmótico, segundo Bewley e Black (1995), sugerem que nos ciclos de umedecimento e secagem, os processos metabólicos iniciais de germinação iniciam durante a embebição e são interrompidos, mas não são revertidas pela subsequente secagem, de tal maneira que as sementes ao serem recolocadas em ambiente favorável à germinação, concluirão o processo mais rapidamente.

A semente, além de representar um meio de propagação, pode servir também como veículo da tecnologia agrícola. A agregação de valor às sementes, utilizando métodos e tecnologias de produção como a de 
revestimento de sementes, é a principal exigência de um mercado cada vez mais competitivo. O uso do revestimento de sementes com materiais artificiais pode facilitar a obtenção de um conjunto de características necessárias ao estabelecimento das plântulas, uniformizando assim os estádios iniciais da produção de sementes. Essa técnica assume maior importância ao tratar-se de sementes de espécies olerícolas e forrageiras (Silva, 2006).

O recobrimento envolve tanto a pelotização de sementes, como o revestimento com filmes de polímeros e outros produtos para encapsulamento da semente. Quando a semente entra em contato com o solo, o recobrimento não deve oferecer resistência à raiz primária e a estrutura que irá formar a parte área da planta, devendo permitir a passagem de água e oxigênio para que o embrião comece a desenvolver-se naturalmente.

Segundo West (1983), um polímero ideal não deve ser permeável ao vapor d'água e permitir a embebição das sementes. Para Baudet e Peres (2004), a técnica de recobrimento deve permitir uma distribuição uniforme, secagem rápida e uma cobertura firme e durável.

O objetivo do trabalho foi avaliar o desempenho fisiológico de sementes de cenoura após osmocondicionamento, tratamento com fungicida $\mathrm{e}$ recobrimento com polímero.

\section{MATERIAL E MÉTODOS}

O trabalho foi realizado no Laboratório Didático de Análise de Sementes (LDAS), da Faculdade de Agronomia Eliseu Maciel (FAEM), da Universidade Federal de Pelotas (UFPel), no período de janeiro a outubro de 2006.

Foram utilizadas sementes de cenoura (Daucus carota L.), cv. Brazlândia, cedidas pela Empresa Hortec ${ }^{\circledR}$ Sementes Ltda, Bagé/RS. As sementes foram submetidas ao condicionamento osmótico em solução aerada de poletilenoglicol (PEG 6000) a -0,8 MPa, a temperatura de $20{ }^{\circ} \mathrm{C}$ (Villela et al., 1991) por um período de 10 horas. Após o condicionamento, as sementes foram lavadas com água destilada e submetidas à secagem em estufa com circulação de ar a $30^{\circ} \mathrm{C}$, por 12 horas, até atingirem a umidade de $\mathbf{7 \%}$, monitorado através de sucessivas pesagens. Logo após, foram tratadas com o fungicida Captan ${ }^{\circledR}$ na dose de $0,002 \mathrm{~g} . \mathrm{kg}^{-1}$ de sementes e recobertas com o polímero Colorseed da Rigrantec ${ }^{\circledR}$ na dose de 50 $\mathrm{mL} \cdot \mathrm{kg}^{-1}$.

As sementes foram submetidas aos seguintes tratamentos: sem osmocondicionamento (SO), com osmocondicionamento (CO), sem polímero (SP), com polímero (CP), sem fungicida (SF) e com fungicida (CF). Constituindo as seguintes combinações: 1) SO SP SF, 2) SO CP SF, 3) SO SP CF, 4) SO CP CF, 5) CO SP SF, 6) CO CP SF, 7) CO SP CF e 8) CO SP CF.

A qualidade das sementes foi avaliada por meio dos seguintes testes: Germinação - conduzido com quatro repetições de duzentas sementes (quatro subamostras de 50 sementes) para cada tratamento, em caixas plásticas tipo gerbox, sobre papel mata-borrão umedecido com água destilada na proporção 2,5 vezes o seu peso seco, em câmara Biological Organism Development (BOD) regulada a temperatura de $20{ }^{\circ} \mathrm{C}$. As avaliações foram realizadas no sétimo e décimo-quarto dia após a semeadura conforme as Regras para Análise de Sementes - RAS (Brasil, 1992). Frio - conduzidos com quatro repetições de duzentas sementes (subamostras de 50 sementes) para cada tratamento, em caixas plásticas tipo gerbox, sobre papel mata-borrão umedecido com água destilada na proporção 2,5 vezes o seu peso seco, em refrigerador regulado a temperatura de $8{ }^{\circ} \mathrm{C}$, durante um período de sete dias. Após este período, as caixas foram transferidas para BOD a $20^{\circ} \mathrm{C}$ e mantidas sob condições do teste de germinação (Krzyzanowski et. al., 1999). Envelhecimento acelerado modificado - conduzido com a utilização de caixas plásticas tipo gerbox, com compartimento individual (minicâmaras), contendo 40 $\mathrm{mL}$ de solução saturada de $\mathrm{NaCl}(40 \mathrm{~g}$ de $\mathrm{NaCl}$ em 100 $\mathrm{mL}$ de água) e uma bandeja de tela de alumínio, na qual, as sementes $(3,0 \mathrm{~g})$ foram distribuídas formando uma camada uniforme sobre a superfície da tela. As caixas foram mantidas a $41{ }^{\circ} \mathrm{C}$ por $72 \mathrm{~h}$. Decorrido o período de envelhecimento, as sementes foram submetidas ao teste de germinação, de acordo com a metodologia sugerida por Rodo et al. (2000). Índice de velocidade de germinação (IVG) - conjuntamente com teste de germinação foram realizadas contagens diárias, a partir da primeira semente germinada, sendo considerada como tal aquela que apresentava raiz primária não inferior a 2 $\mathrm{mm}$. O cálculo do IVG foi realizado conforme descrito por Viera e Carvalho (1994). Índice de velocidade de emergência em casa de vegetação - determinado em cinco subamostras de 20 sementes por tratamento, distribuídas em bandejas de poliestireno expandido com células individuais, preenchidas com substrato comercial para hortaliças - PLANTMAX ${ }^{\circledR}$. A temperatura ambiente média observada foi de $25{ }^{\circ} \mathrm{C}$, em casa de 
vegetação climatizada. As avaliações foram realizadas mediante a contagem diária do número de plântulas emergidas até estabilização do número das plântulas e o cálculo do índice de velocidade efetuado, conforme Maguire (1962). Emergência de plântulas em casa de vegetação - avaliada conjuntamente com a determinação do índice de velocidade de emergência em casa de vegetação climatizada, utilizando cinco subamostras de 20 sementes por tratamento. As avaliações foram realizadas no vigésimo primeiro dia após a semeadura, computando-se o número de plântulas emergidas com comprimento da parte aérea não inferior a $50 \mathrm{~mm}$, conforme Nakagawa (1999). Comprimento da parte aérea - conduzido conjuntamente com a determinação da emergência em casa de vegetação climatizada, utilizando cinco subamostras de 20 sementes por tratamento. As avaliações foram realizadas no vigésimo primeiro dia após a semeadura, mensurando-se o comprimento de cada plântula com régua graduadas em $\mathrm{mm}$. Fitomassa fresca - avaliada conjuntamente com a determinação emergência em casa de vegetação climatizada, utilizando cinco subamostras de 20 sementes por tratamento. As avaliações foram realizadas no vigésimo primeiro dia após a semeadura, cada uma das subamostras de plântulas foram pesadas em balança analítica com precisão de 0,0001 g. Fitomassa seca - após a determinação da massa de plântula fresca, as amostras foram secadas em estufa com circulação de ar forçado a uma temperatura de $72{ }^{\circ} \mathrm{C}$ até peso constante.

O delineamento experimental foi fatorial 2 (com e sem osmocodicionamento) x 4 (tratamento de recobrimento), com quatro repetições e as médias comparadas pelo teste de Duncan em nível de 5\% de significância. Para execução das análises utilizou-se "Sistema de Análise Estatística para Microcomputadores Winstat 2, (Machado, 2000).

\section{RESULTADOS E DISCUSSÃO}

Os resultados obtidos para germinação (Tabela 1) evidenciam que houve benefícios do osmocondicionamento, pois as diferenças constatadas entre o recobrimento e/ou tratamento com fungicida em sementes não osmocondicionadas não ocorreram nas sementes osmocondicionadas.

A análise dos dados de índice de velocidade de germinação (Tabela 1) permite constatar para as sementes sem tratamento ou tratadas apenas com fungicida superioridade nas sementes osmcondicionadas relativamente às não osmocondicionadas. Resultados similares foram encontrados por Nunes et al. (2000) trabalhando com osmocondicionamento em sementes de cebola, tratadas com diferentes fungicidas, também encontraram maior velocidade de emergência de plântulas em sementes osmocondicionadas. Resultados semelhantes também foram obtidos por Sampaio e Sampaio (1998), em sementes de cenoura, ao constatarem que após condicionamento houve aumento significativo na velocidade de germinação. Quanto aos dados de índice de velocidade de emergência (Tabela 1), observase sementes sem tratamento ou recobertas somente com polímero apresentam maiores índices comparativamente às não osmocondicionadas. No entanto, observando o recobrimento e/ou tratamento com fungicida para sementes osmocondicionadas notou-se que houve diferenças significativas no índice de velocidade de emergência, pois sementes recobertas com polímero + fungicida ou tratadas com fungicida foram inferiores aos demais tratamentos. Resultados semelhantes foram observados por Medeiros et al. (2006) em sementes de cenoura revestidas que tiveram atraso de 2 a 3 dias para emergir comparativamente às sementes nuas.

TABELA 1. Dados médios dos testes de germinação (TG), índice de velocidade de germinação (IVG) e índice de velocidade de emergência (IVE) de sementes de cenoura cv. Brazlândia sem osmocondicionamento (SO) e com osmocondicionamento $(\mathrm{CO})$ submetidas a diferentes recobrimentos e/ou tratamento com fungicida.

\begin{tabular}{ccccccc}
\hline \multirow{2}{*}{ Recobrimento } & \multicolumn{2}{c}{ TG $(\%)$} & \multicolumn{2}{c}{ IVG } & \multicolumn{2}{c}{ IVE } \\
\cline { 2 - 7 } & $\mathrm{SO}$ & $\mathrm{CO}$ & $\mathrm{SO}$ & $\mathrm{CO}$ & $\mathrm{SO}$ & $\mathrm{CO}$ \\
\hline Sem tratamento & $80 \mathrm{Aa}$ & $82 \mathrm{Aa}$ & $7,9 \mathrm{Ab}$ & $9,4 \mathrm{Aa}$ & $2,1 \mathrm{Ab}$ & $4,7 \mathrm{Aa}$ \\
Fungicida & $64 \mathrm{Bb}$ & $78 \mathrm{Aa}$ & $4,2 \mathrm{Bb}$ & $7,9 \mathrm{Aa}$ & $2,1 \mathrm{Aa}$ & $2,2 \mathrm{Ba}$ \\
Polimero & $82 \mathrm{Aa}$ & $76 \mathrm{Aa}$ & $7,8 \mathrm{Aa}$ & $8,1 \mathrm{Aa}$ & $2,0 \mathrm{Ab}$ & $4,0 \mathrm{Aa}$ \\
Fungicida+polimero & $72 \mathrm{ABa}$ & $70 \mathrm{Aa}$ & $6,6 \mathrm{Aa}$ & $6,2 \mathrm{Ba}$ & $1,6 \mathrm{Aa}$ & $1,8 \mathrm{Ba}$ \\
\hline
\end{tabular}

Médias seguidas pela mesma letra, minúsculas nas linhas e maiúsculas nas colunas, não diferem estatisticamente entre si, pelo teste de Duncan, em 5\% de probabilidade. 
O condicionamento não proporcionou maior desenvolvimento das plântulas, tampouco maior acúmulo de matéria seca e fresca (Tabela 2), da mesma forma que os diferentes recobrimentos. Estes resultados são diferentes dos obtidos por Magalhães et al. (2004), que verificaram maior massa seca de plântulas após o condicionamento de sementes de cenoura. Independentemente do osmocondicionamento, os diferentes recobrimentos não apresentaram diferenças significativas na massa de fitomassa seca, resultados que corroboram os encontrados por Medeiros et al. (2006).
No teste de frio (Tabela 3) as sementes osmocondicionadas apresentam resultados superiores às sementes sem osmocondicionamento, exceto ao se utilizar sementes unicamente recobertas com polímero. Os tratamentos com aplicação de fungicida, em sementes não osmocondicionadas apresentaram resultados inferiores às sementes não tratadas ou recobertas somente com polímero. Nas sementes osmocondicionadas constatou-se que a aplicação apenas de fungicida foi superior ao recobrimento com polímero.

TABELA 2. Dados médios comprimento de parte aérea (CPA), fitomassa fresco (FF) e fitomassa seca (FS) de plântulas obtidas de sementes de cenoura cv. Brazlândia sem osmocondicionamento (SO) e com osmocondicionamento (CO) submetidas a diferentes recobrimentos e/ou tratamento com fungicida.

\begin{tabular}{ccccccc}
\hline \multirow{2}{*}{ Recobrimento } & \multicolumn{2}{c}{ CPA $(\mathrm{mm} /$ plântula $)$} & \multicolumn{2}{c}{ FF $(\mathrm{g} /$ plântula $)$} & \multicolumn{2}{c}{ FS (g/plântula) } \\
\cline { 2 - 7 } & $\mathrm{SO}$ & $\mathrm{CO}$ & $\mathrm{SO}$ & $\mathrm{CO}$ & $\mathrm{SO}$ & $\mathrm{CO}$ \\
\hline Sem tratamento & $57,3 \mathrm{Aa}$ & $57,1 \mathrm{Aa}$ & $0,0179 \mathrm{Aa}$ & $0,0115 \mathrm{Ba}$ & $0,0038 \mathrm{Aa}$ & $0,0036 \mathrm{Aa}$ \\
Fungicida & $56,6 \mathrm{Aa}$ & $59,0 \mathrm{Aa}$ & $0,0158 \mathrm{Aa}$ & $0,0172 \mathrm{ABa}$ & $0,0036 \mathrm{Aa}$ & $0,0035 \mathrm{Aa}$ \\
Polimero & $61,2 \mathrm{Aa}$ & $61,2 \mathrm{Aa}$ & $0,0136 \mathrm{Aa}$ & $0,0349 \mathrm{Aa}$ & $0,0038 \mathrm{Aa}$ & $0,0037 \mathrm{Aa}$ \\
Fungicida+polimero & $56,3 \mathrm{Aa}$ & $59,3 \mathrm{Aa}$ & $0,0184 \mathrm{Aa}$ & $0,0209 \mathrm{ABa}$ & $0,0035 \mathrm{Aa}$ & $0,0035 \mathrm{Aa}$ \\
\hline
\end{tabular}

Médias seguidas pela mesma letra, minúsculas nas linhas e maiúsculas nas colunas, não diferem estatisticamente entre si, pelo teste de Duncan, em 5\% de probabilidade.

TABELA 3. Dados médios teste de frio (TF), envelhecimento acelerado (EA) e emergência em casa de vegetação (E) de sementes de cenoura cv. Brazlândia sem osmocondicionamento (SO) e com osmocondicionamento (CO) submetidas a diferentes recobrimentos e/ou tratamento com fungicida.

\begin{tabular}{ccccccc}
\hline & \multicolumn{2}{c}{$\mathrm{TF}(\%)$} & \multicolumn{2}{c}{$\mathrm{EA}(\%)$} & \multicolumn{2}{c}{$\mathrm{E}(\%)$} \\
\cline { 2 - 7 } Recobrimento & $\mathrm{SO}$ & $\mathrm{CO}$ & $\mathrm{SO}$ & $\mathrm{CO}$ & $\mathrm{SO}$ & $\mathrm{CO}$ \\
\hline Sem tratamento & $59 \mathrm{Ab}$ & $71 \mathrm{ABa}$ & $61 \mathrm{Aa}$ & $67 \mathrm{Aa}$ & $82 \mathrm{Aa}$ & $81 \mathrm{ABa}$ \\
Fungicida & $42 \mathrm{Bb}$ & $75 \mathrm{Aa}$ & $45 \mathrm{Bb}$ & $61 \mathrm{Aa}$ & $86 \mathrm{Aa}$ & $91 \mathrm{Aa}$ \\
Polimero & $57 \mathrm{Aa}$ & $63 \mathrm{Ba}$ & $51 \mathrm{Bb}$ & $70 \mathrm{Aa}$ & $82 \mathrm{Aa}$ & $81 \mathrm{ABa}$ \\
Fungicida+polimero & $48 \mathrm{Bb}$ & $70 \mathrm{Aba}$ & $65 \mathrm{Aa}$ & $65 \mathrm{Aa}$ & $79 \mathrm{Aa}$ & $79 \mathrm{Ba}$ \\
\hline
\end{tabular}

Médias seguidas pela mesma letra, minúsculas nas linhas e maiúsculas nas colunas, não diferem estatisticamente entre si, pelo teste de Duncan, em 5\% de probabilidade.

Quanto ao vigor avaliado pelo teste de envelhecimento acelerado (Tabela 3), pode-se observar efeito benéfico do osmocondicionamento, pois as diferenças entre diferentes recobrimentos e/ou tratamento com fungicida em sementes não osmocondicionadas, não foram observadas em sementes osmocondicionadas. Nas sementes sem osmocondicionamento, após o envelhecimento acelerado, a presença do polímero com fungicida mostrou-se superior às sementes tratadas apenas com fungicida ou somente recobertas com polímero. Esta ocorrência discorda dos resultados obtidos por Medeiros et al. (2006) no recobrimento de sementes de cenoura, ao observarem que sementes revestidas apresentaram maior germinação após o envelhecimento acelerado em relação às sementes sem recobrimento e/ou tratamento.

A emergência em casa de vegetação bem como a germinação (Tabela 3) não apresentaram diferenças significativas entre sementes com e sem 
osmocondicionamentos. Observa-se que as sementes osmocondicionadas recobertas com fungicida + polímero obtiveram menor porcentagem de plântulas emergidas em relação aos demais tipos de recobrimentos e/ou tratamentos.

\section{CONCLUSÕES}

O osmocondicionamento de sementes de cenoura favorece as velocidades de germinação e de emergência das plântulas;

O uso de polímero e fungicida em sementes de cenoura osmocondicionadas não afeta negativamente o vigor das plântulas;

Independentemente do recobrimento e/ou tratamento com fungicida, as sementes de cenoura osmocondicionadas apresentam melhor desempenho.

\section{REFERÊNCIAS}

BAUDET, L.; PERES, W.B. Recobrimento de sementes. Revista Seed News, n.7, v.1, p.20-23, 2004.

BEWLEY, J.D.; BLACK, M. Seeds: physiology of development and germination. 2.ed., New York: Plenum Press, 1995. 445p.

BRASIL. Ministério da Agricultura e Reforma Agrária. SecretariaNacionalde Defesa Agropecuária.Departamento Nacional de Produção Vegetal. Coordenação de Laboratório Vegetal. Regras para Análise de Sementes. Brasília, DF, 1992. 365p.

CARDOSO,A.I.I.;DELLA VECCHIA,P.T.Considerações sobre o florescimento prematuro e suas implicações para o melhoramento de cenoura para primavera. Horticultura Brasileira, v.13, n.2, p.146-149, 1995.

CASEIRO, R.F.; MARCOS FILHO, J. Métodos para a secagem de sementes de cebola submetidas ao condicionamento fisiológico. Horticultura Brasileira, v.23, n.4, p.887-892, 2005.

EMBRAPA- Empresa Brasileira de Pesquisa Agropecuária. Hortaliças em números. Disponível em: $<$ http://www.cnph.embrapa.br/paginas/hortaliças_em numeros/hortaliças_em_numeros.htm>. Acesso em: 24 jan. 2007.

FINCH-SAVAGE, W.E. Influence of seed quality on crop establishment, growth, end yield. In:BASRA, A.S. (Ed.). Seed quality: basic mechanisms and agricultural implications. Binghamton, NY: Haworth Press, p.361384, 1995.

KRZYZANOWSKI, C.F.; VIEIRA, R.D.; FRANÇA NETO, J.B. Associação Brasileira de Tecnologia de Sementes, Comitê de Vigor de Sementes. Londrina: ABRATES, 1999. 218p.

MACHADO, A. Programa de Análise Estatística winstat 2, 2000. Disponível em: <http://www.ufpel.tche. br/ amachado/winstat/ software>. Acesso em: 15 jun. 2006.

MAGALHÃES, F. H. L.; MACHADO, J. C.; VIEIRA, M. G. G. C.; GUIMARÃES, R. M.; OLIVEIRA, J. A.; LEDO,C. A. S. Desempenho de sementes de cenoura portadoras de espécies de Alternaria após o condicionamento fisiológico com adição de Thiram. Ciência Agrotecnica, v.28, n.5, p.1007-1014, 2004.

MAGUIRE, J.D. Speed of germination- aid in selection and evaluation for seedling and vigour. Crop Science, v.2, n.1, p.176-177, 1962.

MEDEIROS, E.M; BAUDET, L.; PERES, W.B.; PESKE, F.B. Recobrimento de sementes de cenoura com aglomerante em diversas proporções e fungicida. Revista Brasileira de Sementes, v.28, n.3, p. 194-100, 2006.

NAKAGAWA, J. Testes de vigor baseados no desempenho das plântulas. In.: KRZYZANOWSKI, F.C.; VIEIRA, R.D.; FRANÇA NETO, J.B. (Ed). Vigor de sementes: conceitos e testes. Londrina: ABRATES, p 2.1-2.24, 1999.

NASCIMENTO, W.M.; GUEDES, A.C. Efeito do método de colheita na produção de sementes de cenoura. Horticultura Brasileira, v.7, n.2, p.23-27, 1989.

NASCIMENTO, W.M. Condicionamento osmótico de sementes de hortaliças: potencialidades e implicações. Horticultura Brasileira, v.16, n.2, p.106-109, 1998.

NUNES, U.R.; SANTOS, M.R.; ALVARENGA, E.; DIAS, D.C.F.S. Efeito do condicionamento osmótico com fungicida na qualidade fisiológica e sanitária de sementes de cebola (Allium cepa L.). Revista Brasileira de Sementes, v.22, n.2, p.239-246, 2000.

RODO, A.B.; PANOBIANCO, M.; MARCOS FILHO, J. Metodologia alternativa do teste de envelhecimento acelerado para sementes de cenoura. Scientia Agrícola, v. 57, n.2, p.289-292, 2000.

SAMPAIO, N.V; SAMPAIO, T.G. Viabilidade e 
armazenamento de sementes de cenoura (Daucus carota L.) submetidas ao pré-condicionamento osmótico. Revista Científica Rural, v.3, p.38-45, 1998.

SILVA, A.E.L. A. logística no tratamento de sementes. Opinião. Informativo Fundação Pró-Sementes. p.3-4, 2006.

VIGGIANO, J. Produção de sementes de cenoura. In: CASTELLANE,P.D.;NICOLOSI, W.D.; HASHEGAWA, M. Produção de sementes de hortaliças. Jaboticabal: FCAV/FUNEP, p.61-76, 1990.
VIEIRA, R. D.; CARVALHO, N. M. de Teste de vigor em Sementes. Jaboticabal-SP: FUNEP/UNESP, 1994, $164 p$

VILLELA, F.A.; DONI FILHO, L.; SEQUEIRA, E.L. Tabela de potencial osmótico em função da concentração de polietilenoglicol 6.000 e da temperatura. Pesquisa Agropecuária Brasileira, v.26, n.11/12, p.1657-1968, 1991.

WEST, S.H. Polymers as moisture to maitain seed quality. Crop Science, v.25, p.91-94, 1983. 